\title{
Migrantes e refugiados em Mohamed: um menino afegão, de Fernando Vaz
}

\author{
Migrants and refugees in \\ Mohamed: um menino afegão, by Fernando Vaz \\ Migrantes y refugiados em \\ Mohamed: um menino afegão, de Fernando Vaz \\ Larissa Warzocha Cruvinel ${ }^{*}$ \\ Andréia Ferreira de Melo Cunha ${ }^{* *}$
}

\section{Resumo}

A literatura juvenil, por se voltar para um público específico, constituído por jovens leitores cada vez mais imersos em um mundo globalizado, assume um papel importante na reflexão sobre a mobilidade humana na contemporaneidade e os impasses advindos da necessidade de se viver junto. Mohamed: um menino afegão, de Fernando Vaz (2002), tematiza o drama de um menino muçulmano que vive em meio à guerra no Afeganistão. Por meio da análise da obra, este artigo objetiva mostrar como essa narrativa apresenta estratégias composicionais que proporcionam ao leitor ao mesmo tempo uma empatia e um estranhamento com a cultura do outro. Para tanto, serão consideradas as reflexões de Maria Zilda Cury (2006), Fanny Mahy (2016), Zygmunt Bauman (2017), entre outros.

Palavras-chave: literatura juvenil brasileira, imigração, pertencimento.

\begin{abstract}
Because young adult literature is geared towards a specific audience made up of young readers, it plays an important role in the reflection on human mobility in the contemporary world and the impasses that arise from the need to live together. Mohamed: um menino afegão, by Fernando Vaz (2002), tells the story of a Muslim boy living through the war in Afghanistan. Through analysis of the narrative, this article aims to show how Vaz's book presents compositional strategies that provide the reader with both empathy for and estrangement from the culture of the other. As such, we engage with the considerations of Maria Zilda Cury (2006), Fanny Mahy (2016), Zygmunt Bauman (2017), among others.
\end{abstract}

Keywords: Brazilian young adult literature, immigration, belonging.

\section{Resumen}

La literatura juvenil, por dirigirse a un público específico, constituido por jóvenes lectores cada vez más inmersos en un mundo globalizado, asume un papel importante en la reflexión sobre la movilidad humana en la contemporaneidad y los impases originados en la necesidad de convivir con otras personas. Mohamed: um menino afegão, de Fernando Vaz (2002), tematiza el drama de un niño musulmán que vive en medio a la guerra en Afganistán. Por medio del análisis de la obra, este artículo tiene como finalidad mostrar como esa narrativa presenta estrategias composicionales que proporcionan al lector, al mismo tiempo, una empatía y un alejamiento de la cultura del otro. Para tanto, serán consideradas las reflexiones de Maria Zilda Cury (2006), Fanny Mahy (2016), Zymunt Bauman (2017), y otros.

Palabras-clave: literatura juvenil brasileña, inmigración, pertenencia.

\footnotetext{
* Doutora em Letras e Linguística e professora da Universidade Federal de Goiás (UFG), Goiânia, GO, Brasil. (Dorcid.org/00000001-8386-9868 E-mail: larissacruvinel@ hotmail.com

** Doutora em Literatura e professora no Colégio Agostiniano, Goiânia, GO, Brasil. Dorcid.org/0000-0002-5758-1112 E-mail: andreiamols@gmail.com
} 
O tema da mobilidade das grandes massas humanas assume uma relevância particular na contemporaneidade. Embora essa mobilidade seja tão antiga quanto o aparecimento do próprio homem, no modelo de mundo em que nos inserimos, ela ganha uma configuração diferenciada. A crescente onda de refugiados e migrantes provoca tensões e confrontos que precisam ser pensados em um contexto de globalização o qual, aparentemente, deveria diminuir as diferenças e aumentar o limiar de tolerância entre os humanos.

Diante desse panorama, este artigo se volta para o estudo de uma narrativa juvenil brasileira que se debruça sobre o tema da migração e não se furta ao papel de tratá-lo em suas nuances mais delicadas. Mohamed: um menino afegão, de Fernando Vaz, é uma obra premiada. Publicada em 2002, na coleção "Em busca da paz", da editora FTD, recebeu o prêmio Orígenes Lessa, "O melhor para o jovem", concedido pela Fundação Nacional do Livro Infantil e Juvenil, em 2003. Além das qualidades estéticas que justificaram sua premiação, o livro apresenta o mérito de ter sido uma das primeiras narrativas brasileiras a se deter sobre o assunto, quando ele ainda não constava na pauta central dos principais noticiários.

$\mathrm{Na}$ análise, será observado como essa narrativa representa o refugiado, contrapondo-se a uma visão desumanizante em relação a ele, comum nos meios midiáticos. As reflexões de Zygmunt Bauman (2017) servem de referência para a apreciação da narrativa de Vaz a partir de uma ótica externa aos estudos específicos de literatura infantil e juvenil. No contexto desses estudos, a pesquisa de Fanny Mahy (2016) sobre livros juvenis franceses que tratam do tema é recuperada, evidenciando pontos de contato e de afastamento entre as narrativas por ela estudadas e a obra de Vaz.

A formação literária de crianças e jovens constitui-se em um desafio para a sociedade que acredita no potencial reflexivo da literatura, e também para a escola, instituição que se responsabilizou, historicamente, por essa formação. A literatura infantil e juvenil preenche um espaço importante na trajetória para o leitor adulto e, também por isso, merece uma atenção especial das instituições que defendem a leitura como uma possibilidade de ser e atuar no mundo.

Essa literatura caracteriza-se por forte ambiguidade, porque, ao mesmo tempo que deve cumprir o papel de ampliar a discussão sobre os valores sociais vigentes, está intimamente atrelada ao conceito do que seja infância e juventude em determinada época. Considerando-se o primeiro aspecto, a literatura que se debruça sobre seu tempo e os desafios que ele encerra cumpre um papel importante para a formação de jovens leitores mais reflexivos e abertos para o outro. Nesse sentido, poucos temas têm tanto apelo em nosso momento histórico quanto o da migração.

A esse respeito, a obra de Zygmunt Bauman (2017), Estranhos à nossa porta, encerra uma discussão profícua. Bauman destaca como, frequentemente, os migrantes têm sido tratados como uma ameaça em potencial nos países em que buscam refúgio. Essa reação em face dos processos migratórios é fruto, em grande parte, de políticas oportunistas, que se valem do medo e do pânico para um controle maciço da população. A mídia não é isenta nesse processo: constantemente as manchetes dos jornais se referem ao fenômeno por meio de expressões ofensivas e desumanas, como "crise migratória", "fluxos migratórios ilegais", como se os "forasteiros" fossem os responsáveis pela insegurança inerente ao modo de vida moderno. Para o sociólogo polonês, esse tratamento engendra uma separação tácita entre os que chegam e as pessoas que estão alojadas atrás das portas de suas casas.

Bauman mostra que a migração compõe o modo de vida moderno, que gera o que ele denomina de "pessoas redundantes", ou seja, aquelas que não fazem falta em um sistema pautado pela lógica da funcionalidade e da competição, são as "localmente inúteis, excessivas ou não empregáveis, em razão do processo econômico; ou localmente intoleráveis, rejeitadas por agitações, conflitos e dissensões causados por transformações sociais/políticas e subsequentes lutas por poder" (Bauman, 2017, p. 9). Um dos maiores problemas dessa intolerância é que atitudes desmedidas, como o fechamento de fronteiras, a construção de muros e outros artifícios que buscam instaurar uma distância entre o "eu" e o "outro", o estranho, o diferente, substituem a discussão sobre os direitos humanos e sobre as possibilidades, mesmo que problemáticas, de se compartilhar um espaço comum. 
Para Bauman, a expectativa para o futuro dos imigrantes bifurca-se em dois caminhos: no primeiro, a imigração se assemelharia a uma "guerra de guerrilha permanente, voltada para reduzir os direitos dos migrantes e mantê-los num estado de insegurança e vulnerabilidade" (Bauman, 2017, p. 92); no segundo, abre-se a possibilidade de "obter maior apoio para uma abordagem do gerenciamento da imigração com base em direitos" (Bauman, 2017, p. 92).

Quando menciona os direitos humanos e a responsabilidade moral pelo outro, o sociólogo não quer resolver o impasse pela evocação simples e pura da compaixão e da solidariedade; na contramão disso, propõe uma discussão mais complexa sobre as mudanças que temos vivido na contemporaneidade, marcadas por quebras de paradigmas de noções como pertencimento e alteridade.

Como considera Maria Zilda Ferreira Cury (2006, p. 10), os processos migratórios abalam a "percepção que temos de nossa própria identidade, tornando pouco seguras as projeções que fazemos de nós mesmos e do que julgamos ser a 'nossa' cultura". É no estranhamento causado pelo contato com o outro que vislumbramos o que existe para além de nós mesmos. Para Cury (2006, p. 11),

Hoje, pois, a imigração é fenômeno para cujas raízes históricas temos que olhar. No entanto, é fenômeno que ganha especificidade num tempo e espaço como os nossos, já que a presença do imigrante e as imagens por ele elaboradas participam da criação de "identidades" neste entre-espaço cultural e histórico atravessado pelas contradições que constitutivamente estruturam a realidade contemporânea.

Em vista das mudanças cada vez mais profundas no modo de vida contemporâneo, a literatura ocupa um papel importante na reflexão sobre a identidade cultural nos mais diversos contextos, sejam eles demarcados por fronteiras delimitadas geograficamente ou vivenciadas de forma subjetiva. Nesse sentido, a literatura juvenil assume uma relevância particular, visto que, por se dirigir a jovens leitores imersos em um mundo aberto para o contato quase instantâneo com o outro, proporcionado pelos aparatos tecnológicos, não pode se isentar de refletir sobre o papel do apelo de outras culturas na formação identitária das novas gerações.

Obras como Mohamed: um menino afegão, contribuem para pensar essas novas categorias de identidade. O livro é introduzido com um texto de apresentação do autor sob o título "A irracionalidade da guerra", que antecipa a temática central da obra. Nesse texto, o autor sustenta uma tese ousada, de que a base de nossos desentendimentos seria, sobretudo, familiar, já que temos uma descendência comum em Abraão, ou seja, em sua perspectiva, somos todos, judeus, cristãos e muçulmanos, irmanados.

Depois desse texto, segue-se um sumário com 26 capítulos, numerados até o 23, que encerra a fábula propriamente. Esses capítulos numerados são intitulados de forma semelhante, sempre com a repetição de "O menino" em todos os títulos: "O menino e seu pai", "O menino e sua casa", "O menino e seu choro", e assim por diante. A narrativa apresenta estratégias composicionais que buscam aproximar o jovem leitor da realidade do Afeganistão, marcada pela guerra, pela fome e pela morte. No primeiro capítulo "O menino e sua mãe", o narrador em terceira pessoa apresenta uma visão próxima do olhar de uma criança, aproximando o eu e o outro, aquele que conta a história de uma perspectiva externa e um menino de 4 anos que mora em um país distante do Brasil.

De início, o narrador trata o protagonista como um estranho, o que pode ser percebido pela falta de nomeação e pelo foco em uma perspectiva externa à criança:

$\mathrm{O}$ menino. E a guerra. O que sabe o menino da guerra? Nada. E a guerra também nada sabe do menino. Por isso, numa tarde, homens armados invadiram a cidade de Cabul, atirando com fuzis e metralhadoras, tanques e canhões. Lançavam bombas e granadas. E o que havia pela frente ia sendo destruído. Plantas, árvores, muros, paredes, móveis, telhados. Tudo, tudo ia sendo reduzido a cacos, desfeito em pedaços, despedaçado em pedras, que o vento e o tempo haveriam de reduzir a pó (Vaz, 2002, p. 9).

O menino e a guerra são apresentados como personagens antagônicos porque o menino tem medo e a guerra não, ele pode morrer ou perder seus familiares, mas a guerra apenas 
tem uma "língua de fogo" e uma "bota de ferro" (Vaz, 2002, p. 9) para destruir a cidade de Cabul, onde o protagonista mora inicialmente. De início, o confronto entre o menino e a guerra enseja uma simpatia do leitor pela criança, que é retratada em sua fragilidade diante de um oponente frio e destrutivo. Para tentar se proteger, ele se agarra às "saias de sua mãe para não ver o pó que o bombardeio às ruas de Cabul erguia e que o rastro de sangue da própria guerra assentava" (Vaz, 2002, p. 9).

A proteção da mãe é realçada quando ela o coloca para dormir, senta-se perto do filho e conta a respeito de "Alá e da infinita felicidade que Ele lhes daria no Paraíso" (Vaz, 2002, p. 9). $\mathrm{O}$ medo do menino se desvanece com o carinho materno e ele dorme em meio ao barulho ocasionado pela guerra. O leitor da narrativa, por mais que vislumbre uma realidade diferente da sua, em um país distante, reconhece sua mesma humanidade na criança representada na narrativa, que tem medo, tem uma mãe e se agarra a ela nos momentos de perigo.

O menino é acordado pelos estrondos das explosões, quando vê sua casa destruída e percebe que sua mãe não resistiu àquele ataque:

Compreendeu tudo. Mas não podia aceitar. E chorando e soluçando, chamando por sua mãe, o menino continuou a afastar sobras de paredes, cacos de tijolos. Restolhos, retalhos e resíduos. Cinza, pó e poeira. Estilhaços de aço e de chumbo. Resto de coisas desfeitas em tragédia. E a guerra não lhe respondia onde estava sua mãe. Indiferente, prosseguia rugindo na madrugada fria da cidade de Cabul (Vaz, 2002, p. 10).

Em todo o primeiro capítulo, o protagonista não é nomeado, numa clara busca de empatia com o leitor que pode se identificar com um menino como qualquer outro, que tem uma casa, uma mãe e um pai. No segundo capítulo, ele é chamado de Mohamed por Dona Farida, uma vizinha da família que encontra a criança em meio aos escombros da casa destruída.

Aos poucos, a narrativa elucida o contexto da criança, apresentando, gradativamente, elementos da cultura afegã e da religião muçulmana, como a burca que Dona Farida usa, o Alcorão e seus fundamentos religiosos: "Dona Farida e seu Zahir falavam em Deus e o ensinavam a rezar. Liam e explicavam o Alcorão. Consolavam-no, dizendo que sua mãe vivia a infinita felicidade no Paraíso" (Vaz, 2002, p. 16). Dessa forma, ao mesmo tempo que a narrativa busca a empatia do leitor com a personagem, apresenta também um estranhamento com uma outra cultura, provavelmente conhecida somente por meio de programas midiáticos pela maior parte dos jovens leitores brasileiros.

Depois da morte da mãe de Mohamed, seu pai, Omar, retorna de viagem de Peshawar, onde costuma buscar mercadorias para vender e, juntos, eles reconstroem a casa da família. Para garantir sua sobrevivência e a do filho, Omar precisa fazer recorrentes viagens. Sua ausência aumenta a solidão da criança que, enquanto é pequena, precisa ficar na casa de Dona Farida e de seu Zahir. Nesses momentos, os vizinhos inserem Mohamed de forma mais intensa na leitura do Alcorão, mas o menino enfrenta um dilema, porque não consegue aceitar pacificamente os ensinamentos que lhe são transmitidos e suas dúvidas abundam: "Ele se perguntava por que Deus precisava usar a guerra para levá-la? Por que levar sua mãe e deixá-lo sozinho?" (Vaz, 2002, p. 20).

No capítulo 5, "O menino e suas dúvidas", Mohamed faz 7 anos e começa a frequentar o Madraçal, onde as crianças são alfabetizadas por meio da leitura do Alcorão. Em meio aos estudos, crescem as incertezas do protagonista sobre a responsabilidade de Alá pela morte de sua mãe. Para ele, se tudo o que ocorre no mundo é vontade de Deus e Deus é a imagem da benevolência, então ele não engendraria a guerra para matar os homens: "Onde estava escrito que Alá levaria a guerra aos homens? Não sabia. Lembrava-se de que Deus prometia paz, amor, felicidade. Então, por que essa guerra sem fim?" (Vaz, 2002, p. 26). As pessoas à sua volta não entendem os seus questionamentos, como seu pai, que se fecha em mutismo e recita trechos do Alcorão diante das perguntas do filho. Mohamed não se encaixa em uma sociedade marcada pela fé inquestionável e, por isso, não consegue compreender a guerra e suas agruras a partir de um ponto de vista estritamente religioso. 
Em meio ao conflito interminável, relacionado à tomada de Cabul pelo Talibã, os oponentes são divididos em fiéis e infiéis. O ataque às Torres Gêmeas, nos Estados Unidos, é retomado sob a perspectiva dos afegãos já sob o domínio Talibã e, nos Madraçais, os "terroristas" são vistos como "mártires" (Vaz, 2002, p. 39). Dessa forma, a narrativa juvenil não se isenta de abordar a concepção religiosa que justifica os ataques e os assassinatos operados pelos terroristas. Enquanto as pessoas rezam para agradecer o sucesso na batalha, há nova incursão pela interioridade de Mohamed, que questiona se Deus é mesmo onipotente e todo-poderoso, uma vez que, se assim o fosse, não existiriam os infiéis, todas as pessoas seriam fiéis e a guerra não seria necessária.

Fanny Mahy (2016), em "L'immigration dans la littérature jeunesse", analisa como seis obras juvenis francesas lidam com a imigração e tratam o difícil tema de pessoas de diferentes origens viverem juntas. A autora mostra que as obras analisadas "visam a uma compreensão empática do fenômeno migratório, por meio de um diálogo mais ou menos pronunciado entre o desejo de informar e de emocionar a criança por meio de diversos procedimentos estéticos usados na obra, tanto visuais quanto escritos" (Mahy, 2016, p. 435, tradução nossa). Nas obras analisadas pela pesquisadora, é a representação do imigrante que está em primeiro plano, o que é, em parte, positivo porque "constitui um contraponto à visão midiática do imigrante como um problema" (Mahy, 2016, p. 458, tradução nossa).

Além disso, os imigrantes não são caracterizados somente por suas virtudes, mas apresentados em seus aspectos mais negativos, o que enceta uma discussão complexa sobre o contato com o outro no mundo contemporâneo. No entanto, a estudiosa observa a ausência de alguns temas importantes relacionados à imigração nas obras juvenis de seu corpus. Segundo ela, "nenhuma dessas ficções problematizam verdadeiramente as incompatibilidades religiosas, culturais e políticas" (Mahy, 2016, p. 458, tradução nossa). Provavelmente por motivos mercadológicos, os escritores das obras estudadas se isentam de tratar temas controversos, como a religião muçulmana e seus fundamentos.

Nesse sentido, é relevante assinalar que Fernando Vaz não se exime de trazer para a narrativa o choque de visões religiosas díspares que permeiam os partidos que lutam na guerra. Além disso, a compreensão do outro é realçada na narrativa, visto que, uma vez que Mohamed é educado na religião muçulmana, o leitor entra em contato com uma outra realidade pouco usual no Brasil. Isso se dá tanto por meio da descrição de episódios cotidianos, como a permanência das crianças no Madraçal, quanto por um estranhamento mais profundo com a forma de o protagonista conceber o mundo, marcada pela religiosidade.

O dia a dia da criança, permeado pela solidão e pela privação de bens de consumo, até mesmo de alimentos, também é passível de suscitar uma simpatia do leitor pelo destino da personagem. Ao encontrar um pneu velho de bicicleta em um terreno baldio, Mohamed brinca pelas ruas de Cabul com ele, imaginando que dirige um caminhão que leva comida para as pessoas da cidade. É por meio da fantasia e do sonho que ele consegue se proteger da solidão e da miséria. Apesar da crueza da guerra, há uma comunidade humana entre as pessoas que conhecem Mohamed, como seu Zahir e Dona Farida, que cuidam do menino durante as viagens de seu pai até que ele tenha idade para ficar sozinho em casa.

Com o recrudescimento da guerra, agora perpetrada pela potência americana, as famílias fogem de Cabul rumo à divisa do Paquistão. Em uma das vezes que o pai do menino viaja para comprar mercadorias, o jumento Jahad retorna sozinho, trazendo a incerteza sobre o que teria acontecido. É nesse momento que o menino decide também abandonar sua cidade em busca do pai. Ele e o jumento seguem o perigoso caminho até Jalalabad, "cheio de minas, malfeitores, salteadores e assassinos" (Vaz, 2002, p. 58).

Quando chegam a Jalalabad, o menino está quase desacordado devido à privação de comida e água, mas o jumento dirige seus passos e o protege ao conduzi-lo a uma hospedaria de um amigo de Omar. Apesar dos esforços do dono da hospedaria, Mohamed foge de lá em busca do pai. Enfrenta os perigos do caminho e segue em direção ao Passo de Khyber, um precipício que conduz a Peshawar. 
Já na fronteira com o Paquistão, Mohamed se depara com violentos soldados, instruídos a não deixarem os refugiados atravessarem rumo a Peshawar. Nesse episódio, a forma desumana como os refugiados são tratados vem à tona: "Além de armas de fogo, os guardas seguravam longas chibatas, com as quais era possível bater de longe nos refugiados, que, do lado afegão, pediam, imploravam para os deixarem passar. Inflexíveis, os homens tratavam-nos com grosseria e violência" (Vaz, 2002, p. 83). Há uma separação entre os soldados, que não se interessam por saber dos motivos que levam Mohamed a querer transpor a fronteira, e a história individualizada e não coisificada do menino que não concebe a ideia de viver sem uma família. Em meio ao impasse da criança diante dos soldados, o protagonista é acolhido por Dona Farida, que conta a ele que perdeu o marido, sua irmã e seu cunhado durante a travessia e que agora era a única responsável pela sobrinha, a menina Jamila.

No outro dia, obstinadamente, o menino tenta atravessar a fronteira, alegando que precisa encontrar seu pai. Ele é ferido por várias chibatadas, mas insiste ao ponto de cair desfalecido. Dessa forma, pouco importam os motivos pessoais e humanos de Mohamed para atravessar a fronteira, ele é tratado como algo desprovido de humanidade, um intruso que não pode ultrapassar aquela barreira geográfica criada artificialmente.

$\mathrm{Na}$ enfermaria do campo de refugiados, o garoto é apresentado a Sebastião, um brasileiro que trabalha na comissão de refugiados da Organização das Nações Unidas (ONU). É ele quem vai cuidar do protagonista e vai ajudá-lo a atravessar a fronteira. Os dois procuram o pai do menino com o auxílio do jumento, que os leva à hospedaria onde Omar costumava ficar em Peshawar. Lá Mohamed se dá conta de que seu pai não deve ter sobrevivido.

Quando descobre que a criança é órfã, Sebastião se sente responsável pelo destino dela:

Afinal, que culpa cabia ao menino? Por acaso foi ele quem fez a guerra? Por que, então, abandoná-lo se, quando nasceu, já havia a guerra, em seu país e no mundo? E ao perguntar-se essas coisas, sentiu-se responsável pelo destino do menino. Aliás, os adultos do mundo deveriam ser responsáveis pelo destino de cada uma das crianças, pois não são as crianças que fazem as guerras ou semeiam injustiças (Vaz, 2002, p. 99).

A comunidade humana existente entre as pessoas da mesma origem, como Mohamed, Dona Farida e seu Zahir, estende-se, nesse momento, para um homem de uma terra distante, um brasileiro que não é muçulmano. Sebastião, ao questionar se a guerra existe por desejo de Alá ou se seria algo dos homens, vai ao encontro das dúvidas que permearam toda a trajetória da criança:

- Sabe por que você não entende, Mohamed? Porque os homens atribuem a Alá coisas inexplicáveis que eles, homens, fazem. Uma delas é a guerra, que não é, nem pode ser, coisa de Deus, porque Deus quer que os homens cresçam e se multipliquem. E a guerra, o que faz a guerra? Destrói, ou seja, mata e diminui. Logo, a guerra é a negação das principais palavras que Alá disse ao primeiro homem. Se Alá deu aos homens toda a Terra, por que iria fazer a guerra para matá-los? Não, Mohamed, a guerra é coisa dos homens. Alá nada tem a ver com a guerra (Vaz, 2002, p. 100).

O brasileiro, movido pela compaixão, convida Mohamed a viver no Brasil, um lugar que, segundo ele, goza de "relativa paz" (Vaz, 2002, p. 101). Há poucos dados sobre a vida em solo brasileiro, a narrativa é mais centrada na representação dos confrontos no Afeganistão e na construção dos conflitos internos enfrentados de Mohamed. Nesse sentido, a obra juvenil coaduna com tendências da literatura brasileira contemporânea de se desprender da abordagem voltada para o espaço nacional e para a interpretação do Brasil. Beatriz Resende, em "Possibilidades da escrita literária no Brasil", aponta que algumas marcas da contemporaneidade são o

deslocamento das narrativas do espaço local, nacional. O rompimento com a tradição literária de afirmação da língua, da nação, dos valores culturais nacionais. Em vez da literatura que fala do Brasil, que usa a cor local como valor (rentável) de troca, a literatura que busca se inserir, sem culpa, no movimento dos fluxos globais (Resende, 2014, p. 14).

No desfecho, Mohamed é adotado por Sebastião. Ao contrário do antagonismo entre os que chegam de fora e os que estão atrás de suas portas, estrategicamente fabricado pela mídia e pelos governantes, como aponta Bauman, o desfecho da obra acena para uma união fraterna 
entre pessoas de diferentes origens. A relação de paternidade que será exercida por Sebastião não é algo passageiro, como a simpatia momentânea que as pessoas sentem quando vislumbram na mídia episódios ligados à imigração. Como considera o sociólogo:

O que está acontecendo hoje - em acentuada oposição ao espaço, em permanente expansão, da interdependência humana- é a redução daquele domínio das obrigações morais que estamos prontos a admitir, cuja responsabilidade estamos dispostos a assumir e aceitar como o objeto de nossa atenção e ação corretiva constantes, cotidianas. Não apenas durante as festivas explosões de curta duração de solidariedade e preocupação desencadeadas pelas imagens midiáticas de sucessivas tragédias espetaculares na interminável saga dos migrantes. O problema é que, durante os prolongados espaços de tempo que separam esses festivais morais, tendemos a viver num mundo claramente separado, em aparência de modo irreversível, entre "nós" e "eles" (Bauman, 2017, p. 79).

Ao lado dessa visão humanitária, a obra, por meio de um trabalho estético bem realizado, propõe uma reflexão aberta sobre a trajetória de Mohamed e os problemas que ele enfrenta, ao mesmo tempo que busca uma aproximação do leitor com a criança representada na narrativa. Para Mahy, "Compreender a imigração requer da parte da criança a mobilização de suas faculdades intelectuais assim como a abertura de suas emoções, por meio de uma capacidade de identificação" (Mahy, 2016, p. 443, tradução nossa). Para favorecer a empatia com a trajetória das personagens, os escritores das obras francesas analisadas "recorrem a diversos procedimentos, dos quais o mais proeminente é o heroísmo da personagem submetida a condições difíceis e também pelo acesso a sua interioridade, marcada pelo medo, pela coragem, de memórias e de sentimentos" (Mahy, 2016, p. 444, tradução nossa). Dessa forma,

As personagens de crianças-emigradas, por serem corajosas na adversidade, merecem e suscitam a empatia e a admiração das crianças leitoras. Essas últimas ficam então mais inclinadas a se abrir para a aventura imigratória, não apenas de um ponto de vista factual, mas humano, com sensações, emoções e força de sentimentos ligados às temáticas da identidade e da alteridade (Mahy, 2016, p. 444, tradução nossa).

A estudiosa mostra que, por meio de diferentes pontos de vista e diversas formas de representar os imigrantes, as obras estudadas contribuem para que o jovem leitor compreenda melhor o mundo em constantes transformações em que ele vive. Da mesma forma, na narrativa de Vaz, o leitor se defronta com o drama de uma criança que, sob vários aspectos, provavelmente nada tem a ver com ele, a começar por suas crenças religiosas. Entretanto, dentro dessa diferença há o elemento comum, os sentimentos de medo, horror e esperança, que mobilizam o ser humano. Em um mundo plural e multifacetado, com hábitos culturais distintos, a condição humana realça uma irmandade que ultrapassa as barreiras geográficas.

Os paratextos da obra, compostos tanto pelo texto inicial, já destacado, quanto pelo posfácio, contribuem para orientar o leitor em sua trajetória de leitura. Especificamente, no posfácio, há uma intenção de destacar, de forma mais detida, as imagens divulgadas na mídia de maneira fria e rápida:

Algumas fotos veiculadas nos meios de comunicação nos enchem de surpresa. Mesmo que esses fatos se passem num país tão distante do nosso, como o Afeganistão, as imagens nos despertam sentimentos profundos. Como vivem as crianças afegãs? Como brincam? Como passeiam? Como são educadas? (Vaz, 2002, p. 102).

Dessa forma, há na narrativa a clara intenção de sensibilizar o leitor para outra realidade, outra cultura, quebrando estereótipos culturais por meio de uma tentativa de ver o outro. Na direção das reflexões de Bauman, a obra vai além de uma defesa da solidariedade humana. Por meio de um jogo complexo entre a empatia e o estranhamento pelo destino do protagonista, o leitor pode se envolver de forma múltipla e problematizadora com os dilemas da imigração.

Como pontua Bauman, os imigrantes são tratados frequentemente nos meios midiáticos como um problema, são intrusos que geram insegurança e abalam as supostas concepções estáveis de nacionalidade. A trajetória de Mohamed, na contramão das rápidas e frias notícias 
midiáticas, abre espaço para que o leitor se coloque no lugar do outro, proporcionando uma visão mais complexa sobre a mobilidade humana na contemporaneidade.

\section{Referências}

CURY, Maria Zilda Ferreira (2006). Uma luz na escuridão: imigração e memória. In: VAZ, Artur Emílio Alarcon; BAUMGARTEM, Carlos Alexandre; CURY, Maria Zilda Ferreira (Org.). Literatura e imigrantes: sonhos em movimento. Belo Horizonte: Faculdade de Letras da UFMG - POS-LIT; Rio Grande: Fundação Universidade Federal do Rio Grande, Programa de Pós-Graduação em Letras: História da literatura. p. 9-34.

MAHY, Fanny (2016). L'immigration dans la littérature jeunesse. Vers une compréhension du monde dans lequel on vit. @nalyses - Revue des Littératures Franco-Canadiennes et Québécoise, Ottawa, v. 11, n. 2, printemps-été. Disponível em: https:/ / bit.ly/2m62ORn Acesso em: 26 fev. 2019.

RESENDE, Beatriz (2014). Possibilidades da escrita literária no Brasil. In: RESENDE, Beatriz; FINAZZIAGRÓ, Ettore (Org.). Possibilidades da nova escrita literária no Brasil. Rio de Janeiro: Revan. p. 9-24.

VAZ, Fernando (2002). Mohamed: um menino afegão. São Paulo: FTD.

ZYGMUNT, Bauman (2004). Estranhos à nossa porta. Rio de Janeiro: Zahar. 